\title{
Coupled transcript and metabolite identification: insights on induction and synthesis of resveratrol in peanut, wild relatives and synthetic allotetraploid
}

\author{
P.A.S.V. Carvalho ${ }^{1}$, A.C. Brasileiro ${ }^{2}$, S. Leal-Bertiolii ${ }^{2}$, D.J. Bertioli ${ }^{3}$, \\ J.P. Silva ${ }^{2}$, T.S. Agostini-Costa ${ }^{2}$ and M.A. Gimenes ${ }^{2}$ \\ ${ }^{1}$ Departamento de Genética, Instituto de Biociências, \\ Universidade Estadual Paulista, Botucatu, SP, Brasil \\ ${ }^{2}$ Embrapa Recursos Genéticos e Biotecnologia/CENARGEN, \\ Parque Estação Biológica, Brasília, DF, Brasil \\ ${ }^{3}$ Universidade de Brasília, Campus I, Brasília, DF, Brasil \\ Corresponding author: M.A. Gimenes \\ E-mail: marcos.gimenes@embrapa.br
}

Genet. Mol. Res. 16 (3): gmr16039802

Received August 15, 2017

Accepted September 4, 2017

Published September 27, 2017

DOI http://dx.doi.org/10.4238/gmr16039802

Copyright (C) 2017 The Authors. This is an open-access article distributed under the terms of the Creative Commons Attribution ShareAlike (CC BY-SA) 4.0 License.

\begin{abstract}
Resveratrol is an antioxidant that is a promising antitumoral, cardioprotective and neuroprotective agent. It has been found in a restricted number of plants including peanut (Arachis hypogaea L.) and its wild relatives. The objective of this study was to understand the relationship between resveratrol content and the expression of putative resveratrol synthase genes in four Arachis genotypes. Two diploids and two tetraploid were analyzed. Contents of resveratrol on non- and UV-treated leaves were estimated using HPLC. Resveratrol synthase (RS) was analyzed using RT-qPCR with primers developed in this study. Sequences of six Arachis species were amplified using two degenerated primer pairs that were designed based on Arachis and general RS available at GenBank. Those sequences were used to qPCR primers design. Test and control leaves were collected
\end{abstract}

Genetics and Molecular Research 16 (3): gmr16039802 
from plants cultivated in greenhouse and three biological replicates were evaluated for each genotype. The synthesis of resveratrol in leaves was induced by treatment with UV for $2.5 \mathrm{~h}$. All genotypes studied synthesized resveratrol. Concentrations ranged from $193.66 \mu \mathrm{g} / \mathrm{g}$ in synthetic allotetraploid to $371.97 \mu \mathrm{g} / \mathrm{g}$ in A. duranensis. Natural and induced allotetraoploids showed lower levels of resveratrol than their diploid parents. Untreated samples did not produce significant amounts of resveratrol. The analysis of resveratrol content and levels of RS mRNA allowed the identification of one gene induced by the UV treatment. The data showed different amounts of RS in the different genotypes suggesting early and late response to the UV induction in the different species. The understanding of the variation found among species will help to identify species that have high resveratrol content and their ideal pos-induction times. This also will allow analysis of other tissues where high levels resveratrol would be very important, such as in seeds.

Key words: Resveratrol; Arachis; qPCR; HPLC; Resveratrol synthase

\section{INTRODUCTION}

Peanut (Arachis hypogaea L.) has high nutritional value due to its high content of proteins, oils, carbohydrates, minerals, and vitamins (Wu et al., 2009). Besides, it also synthesizes resveratrol (trans-3,5,4'-trihydroxystilbene) (Jeandet et al., 2012), that is a phytoalexin that is part of defense system to biotic and abiotic stresses, such as UV irradiation (Chung et al., 2003). It is also a powerful antioxidant that has been considered therapeutic for humans (Baur and Sinclair, 2006).

Resveratrol was first reported in peanut grains by Ingham (1976). Recently, it was also found in UV-treated leaves of ten wild species of the section Arachis (Lopes et al., 2013), including A. duranensis and A. ipaënsis, the progenitors of the cultivated peanut (Kochert et al., 1996).

Section Arachis is one of the nine taxonomic sections of genus Arachis and it comprises 31 species (Krapovickas and Gregory, 2007; Valls et al., 2013) that are phylogenetically very close to peanut (Bechara et al., 2010). Section Arachis species are found in different environments and because of that they may harbor resistant genes related to abiotic and biotic stress that are not found in cultivated peanut (Pande and Rao, 2001). The variation in many important traits have been evaluated in Arachis species to verify their value in peanut breeding programs, mainly in Brazil, which possesses the largest gene bank of wild species of Arachis (Fávero et al., 2009).

Resveratrol is synthesized by a one-step reaction (Hanhineva et al., 2009) of resveratrol synthase gene (RS) that is differentially regulated under different stimuli and in different tissues (Chung et al., 2003) and belongs to a large multigene family (Vannozzi et al., 2012). Arachis hypogaea RS genes were already cloned (Schröder et al., 1988; Huang et al., 2012). However, little is known about the RS in wild species of Arachis.

The study of RS expression in wild plants will shed light on resveratrol production in wild species, helping identifying their real potential as sources of resveratrol and alleles to improve cultivated peanut production.

Genetics and Molecular Research 16 (3): gmr16039802 
The objective of this study was to evaluate the variation in resveratrol content and RS gene among five Arachis genotypes to get information that will help the better understanding of resveratrol synthesis among different Arachis genotypes.

\section{MATERIAL AND METHODS}

\section{Material}

Seeds of five Arachis genotypes (Table 1) were germinated in germitest paper. Plantlets were transferred to pots containing $500 \mathrm{~g}$ soil and kept regularly watered in a greenhouse for three months.

Table 1. Species, sample identifications, genome type, and ploidy level.

\begin{tabular}{l|l|c|c}
\hline Species & Sample identification & Genome & Ploidy level \\
\hline A. cardenasii & GKP10017 & AA & $2 \mathrm{~N}$ \\
\hline \multirow{2}{*}{ A. hypogaea } & cv. IAC-Tatu & AABB & $4 \mathrm{~N}$ \\
\cline { 2 - 4 } & cv-IAC Runner & AABB & AA \\
\hline \multirow{2}{*}{ A. duranensis } & V14167 & AA & $2 \mathrm{~N}$ \\
\cline { 2 - 4 } & K7988 & BB & $2 \mathrm{~N}$ \\
\hline A. ipaënsis & K30076 & BB & $2 \mathrm{~N}$ \\
\hline A. magna & KG30097 & AA & $2 \mathrm{~N}$ \\
\hline Atenosperma & V10309 & BBAA & $2 \mathrm{~N}$ \\
\hline Synthetic Allotetraploid & A. ipaënsis K30076 X A. duranensis V14167 & $4 \mathrm{~N}$ \\
\hline
\end{tabular}

\section{Resveratrol induction by UV}

Fifty leaves from 15 plants of each genotype were collected in greenhouses few hours before the UV treatment. They were equally divided in two groups (treated and control) and placed in trays $(45 \mathrm{~cm} \times 30 \mathrm{~cm})$ containing a layer of germitest paper under a layer of approximately $1 \mathrm{~cm}$ of cotton moistened with $200 \mathrm{~mL}$ water. UV induction in leaves was performed as described by Lopes et al. (2013). Leaves were placed at a laminar flow chamber (Trox Model FLV series: 23581) under UV lamps (Philips TUV 30W/ G30 T8 Longlife) for $2 \mathrm{~h} 30 \mathrm{~min}$ at room temperature and control samples were maintained in the same conditions but under the dark. After that, both samples were maintained in the dark at room temperature for $15 \mathrm{~h}$.

Leaves of each genotype had the leaflets detached from the petiole and homogenized within each treated and control group. One gram of leaflets was then transferred to two $50-\mathrm{mL}$ tubes, immediately frozen in liquid nitrogen and stored at $-80^{\circ} \mathrm{C}$.

Samples of each genotype were divided so that half of the material was used to analyze the relative expression of RS and the other half to analysis of resveratrol content.

\section{RS expressions analysis}

\section{Development of primers for RT-qPCR analysis}

RS sequences of wild Arachis species were obtained using two pairs of degenerated primers (RsAra and RsGb) that were designed using two sets of sequences. The first set comprised only Arachis RS sequences identified using BLASTn, that were aligned using the Clustal $\mathrm{X}$ and primers were designed to conserved regions using PriFi (Fredslund et al.,

Genetics and Molecular Research 16 (3): gmr16039802 
2005). The selected primers were RsAra-F 5'CGCCACGAAGGCCATGMARGARTGGGG3' and RsAra-F 5'GGGCCGGGRTGNGCDAT3'. The second set comprised all RS and stilbene synthase of all species available at GenBank at that time. Those sequences were also aligned using Clustal X - jalview. The sequences were submitted to the Consensus-Degenerate Hybrid Oligonucleotide Primers (http://bioinformatics.weizmann.ac.il/blocks-bin/codehop.pl) to design primers to conserved regions of proteins. The selected primers of this second search were RsGb-F 5'CACATGACYGAYCTCAAGAARAAATTTCAGCGCAT3' and RsGb-R 5'GTTGCAGCCTCTTTTCCAACYCTTGGTACC T3'. Both pairs of primers were designed to amplicons to have about $600 \mathrm{bp}$ length.

RsAra and RsGb primers were used to amplify genomic regions of $A$. hypogaea $\mathrm{cv}$. IAC-Tatu, A. hypogaea cv. IAC-Runner, A. cardenasii (accession GKP10017), A. magna (KG30097), A. stenosperma (V10309), A. duranensis (K7988, V14167), and A. ipaënsis (KG30076). PCRs were carried out using $25 \mathrm{ng}$ genomic DNA. The cycling conditions were $5 \mathrm{~min}$ at $92^{\circ} \mathrm{C}$, and 35 times of the following cycle: $1 \mathrm{~min}$ at $92^{\circ} \mathrm{C}, 1 \mathrm{~min}$ at $55^{\circ} \mathrm{C}, 1 \mathrm{~min}$ at $72^{\circ} \mathrm{C}$, followed by a final extension of $5 \mathrm{~min}$ at $72^{\circ} \mathrm{C}$. The fragments obtained from each pair of primers and DNA of the seven genotypes were excised from the purified gel using DNA Geneclean ${ }^{\circledR}$ II kit. The fragments obtained for each species were cloned into the pGEM $^{\circledR}-\mathrm{T}$ Easy Vector. Twelve clones of each genotype were sequenced for each genotype.

The fragment sequences were aligned and a phylogenetic tree was obtained using the Similarity tree - Staden program. RT-qPCR primer pairs were designed using sequences from different clusters of the tree.

Alignments were fed into the Primer3-Plus software (Untergasser et al., 2012). (http:// www.bioinformatics.nl/cgi-bin/primer3plus/primer3plus.cgi) using the parameters defined by Morgante et al. (2011) and the Primique software was used (http://cgi-www.daimi.au.dk/cgichili/primique/front.py) when fragment specific pair of primer was not found. The primers selected are listed on Table 2.

Table 2. Sequences of primers selected based on the phylogenetic tree. Primer pairs identified as RSGbAhT or as RSArAhT were designed using resveratrol synthase gene sequences of Arachis hypogaea (Ah) and primer pairs identified as RSArAs or as RSGbAsA were based on sequences from A. stenosperma (V10309 accession) resveratrol synthase (As).

\begin{tabular}{l|l|l}
\hline Primer designations & Forward & Reverse \\
\hline RSArAs01 & TCC TAA CAT GTG CGC ATA CAA & TTG CAG CCT CTT TTC CAA CT \\
\hline RSArAs02 & TCC TAA CAT GTG CGC ATA CAA & CAG CCT CTT TTC CAA CTC TT \\
\hline RSArAs06 & AGG AGA ATC CTA ACA TGT GC & GTT GCA GCC TCT TTT CCA AC \\
\hline RSArAhT05 & TCC TAA CAT GTG CGC ATA CAA & GTT GCA GCC TCT TTT CCA AC \\
\hline RSArAhT06 & CAA GGG TAT TGA TGG ATG TGA A & AAC GAC GGT GCC TTA TAT GC \\
\hline RSGbAsA6b & CCT GGC GTT GAT TAC GAA CT & AGC AGC CTT GGT GGT ACA TC \\
\hline RSGbAsA12 & CCG TCC GTG AAG AGG TAC ATG & AAC CAC CAG CAC ACG AGC AC \\
\hline RSGbAhG8 & TCC GTC CGT GAA GAG GTA CAT G & AAC CAC CAG CAC ACG AGC AC \\
\hline RSGbAhT14 & GGC GTT GCA TTG CCT GGT GTT G & CAG CCA AGT CCT TAG CCA AGC G \\
\hline
\end{tabular}

\section{Relative expression of RS genes}

Leaves from treated and control samples were immediately frozen in liquid nitrogen and stored at $-80^{\circ} \mathrm{C}$. Total RNA was extracted from $250 \mathrm{mg}$ plant material using the method of Chang et al. (1993) followed by purification on Invisorb Spin Plant RNA Mini columns (Invitek, Berlin, Germany) to eliminate impurities. RNA integrity was checked at 1\% agarose gel stained with ethidium bromide. Total RNA was quantified at $260 \mathrm{~nm}$ using the NanoDrop ${ }^{\circledR}$

Genetics and Molecular Research 16 (3): gmr16039802 
ND - 1000 spectrophotometer (Thermo Scientific, Waltham, MA, USA) and its purity confirmed as a $260 / 280 \mathrm{~nm}$ ratio above 1.8 .

DNAse treatment and cDNA synthesis were carried out in subsequent steps, in the same tube. Genomic DNA contaminants were removed from total RNA by treatment with DNase (TURBO DNAfree ${ }^{\mathrm{TM}}$, Ambion, USA), according to the manufacturer instruction, followed by first strand cDNA synthesis performed at $42^{\circ} \mathrm{C}$ for $60 \mathrm{~min}$ on a Master Cycler thermocycler (Eppendorf AG, Hamburg, Germany) using SuperScript ${ }^{\mathrm{TM}}$ III RT and anchored Oligo(dT) (Invitrogen, Carlsbad, CA, USA), according to the manufacturer instruction. DNase and reverse transcriptase were heat inactivated in the tube and the resulted cDNA was directly used in RT-qPCR assays.

DNA contamination in cDNA samples was checked by RT-PCR using a pair of conserved primers that flank an intron region in Arachis (Actin C24 Fwd-5' GAGCTGAAAGAT TCCGATGC 3' and Actin C24 6Rev-5' GCAATGCCTGGGAACATAGTC3'), as previously described (Morgante et al., 2011), which allows the distinction between PCR products amplified from genomic DNA and cDNA templates.

Real-time PCR was performed according Morgante et al. (2011), with adaptations. qRT-PCR assays were performed in a F7300 Real Time PCR (Applied Biosystems, Foster City, CA, USA) using $5 \mathrm{~mL}$ Platinum SYBR Green qPCR Super Mix-UDG w/ROX kit (Invitrogen) in a $10-\mathrm{mL}$ final volume reaction containing $2 \mathrm{~mL}$ diluted cDNA and $0.2 \mathrm{mM}$ of each primer. The following two reference genes were used: Arachis Ubiquitin (Fwd5'AAGCCGAAGAAGATCAAGCAC3', Rev-5'GGTTAGCCATGAAGGTTCCAG3') (Luo et al., 2005) and Ribosomal 60S (Fwd-5'GAGCTGAAAGATTCCGATGC3', Rev5'GCAATGCCTGGGAACATAGTC3') (Jain et al., 2006). Those two pairs for primers were designed in intron flanking regions which also allows the distinction between PCR products amplified from genomic DNA and cDNA templates. For each sample, three independent analytical replicates were performed. The amplification conditions were: $50^{\circ} \mathrm{C}$ for $2 \mathrm{~min}$, $95^{\circ} \mathrm{C}$ for $10 \mathrm{~min}, 40$ cycles of $95^{\circ} \mathrm{C}$ for $15 \mathrm{~s}$ and $60^{\circ} \mathrm{C}$ for $1 \mathrm{~min}$, and a dissociation curve at $95^{\circ} \mathrm{C}$ for $15 \mathrm{~s}, 60^{\circ} \mathrm{C}$ for $60 \mathrm{~s}$ and $95^{\circ} \mathrm{C}$ for $15 \mathrm{~s}$. The result of the reaction was expressed in $\mathrm{TC}$ value (value for the number of cycles required for the fluorescent signal reaches detection threshold) and calculated by Real Time PCR Miner 2.2 program (Zhao and Fernald, 2005) as fluorescence values of the reactions. Individual results expressed as CT values were grouped according to species analyzed and treatment (treated and untreated) for statistical analysis.

The threshold cycle $(\mathrm{Ct})$ was calculated by the RT-qPCR software automatically (threshold value at 0.2 ). Raw fluorescent data (normalized reporter values, Rn values) were also exported. Amplification efficiencies were calculated from raw fluorescent data (Rn values), using the Real-time PCR Miner program (Zhao and Fernald, 2005). Calculation of relative gene expressions detected using eight primer pairs were performed using REST-MSC (Relative Expression Software Tool-Multiple Condition Solver) software version 2 (Pfaffl et al., 2002). REST uses the Pairwise Fixed Reallocation Randomization Test $^{\circ}$ to calculate result significance and will indicate if the reference gene used is suitable for normalization.

\section{Determination of resveratrol content in leaves}

Resveratrol was extracted using a method modified from Potrebko and Resurreccion (2009). The internal standard $(0.840 \mathrm{~mL}$ of phenolphthalein) was added to each sample immediately after maceration and solution phase were separated suing centrifugation at

Genetics and Molecular Research 16 (3): gmr16039802 
$10,000 \mathrm{rpm}$, at $25^{\circ} \mathrm{C}$ for ten minutes. The liquid phase was transferred to another tube and 5 $\mathrm{mL} 80 \% \mathrm{EtOH}$ were added to the tube containing solid leaf residues, mixed and centrifuged again. This procedure was repeated three times. The same amount of hexane was added to the supernatant and the residue was diluted in $6.8 \mathrm{~mL} 15 \%$ ethanol prior to analysis by high performance liquid chromatography (HPLC). Acetonitrile gradient and $0.02 \%$ aqueous phosphoric acid was used as mobile phase: acetonitrile $0 \mathrm{~min}, 13 \% ; 6-9 \mathrm{~min}, 15 \% ; 17 \mathrm{~min}$, 17\%; 28-33 $\mathrm{min}, 28 \%$; $40 \mathrm{~min}, 50 \%$; $45 \mathrm{~min}, 60 \%$; $46-48 \mathrm{~min}, 80 \%$, 49-54 min; 13\%; flow $1.0 \mathrm{~mL} / \mathrm{min}$. The UV absorption was monitored at $308 \mathrm{~nm}, 280 \mathrm{~nm}$ and also at the length of maximum absorption (PDA). The injection volume was $10 \mu \mathrm{L}$. Resveratrol was quantified by the addition of phenolphthalein to the extracts and standards, as internal standard (Lopes et al., 2013). Each sample was subjected to ultrasound bath for 4 min twice. The analysis of data was done according to Potrebko and Resurreccion (2009).

\section{Correlation between the concentration of resveratrol and the relative expression of RS}

Each treatment included three biological replicates. For data analysis, it was adopted the program for statistical language $\mathrm{R}$ - version 2.13.2, freely download at http://www.rproject.org (R 2012). A model of mixed regression was used to relate the results of resveratrol and RS relative expression.

\section{RESULTS AND DISCUSSION}

The amplicons obtained using both degenerated primers pairs had the expected size (around $500 \mathrm{bp}$ ). The 124 high-quality sequences from the two different sets of primers did not align, suggesting that the primers used allowed the amplification of different regions of the same gene or different genes (data not shown).

Phylogenetic trees were built based on sequences obtained using the two degenerated primer pairs. However, only the tree obtained using nucleotide sequences obtained using the primer pair that was selected based in Arachis sequences is presented (Figure 1) here because they show very similar results. Variation was found among sequences of each sample. In general, no $100 \%$ similarity was observed between sequences in both trees and sequences of each species were spread into different clusters having higher similarity to other species sequences than to those of the same species. The intra-specific variation might be due to the fact that RS gene family also happens in the wild species, as reported for the cultivated peanuts (Lanz et al., 1990). The amplification in all samples using primers designed using sequences from two different species suggested that RS gene family originated before speciation, at least in section Arachis that comprises the samples analyzed. RS gene family has not been studied in wild Arachis, but evidences show peanuts and their wild relatives have many similarities on gene content (Bertioli et al., 2016). Thus, we assume wild Arachis also have a RS gene family. The variation observed also is because the alignment used to get Figure 1 was based on nucleotide sequences instead of amino acid which probably would increase the similarity among the sequences since the conserved domains would show up.

Nine nucleotide sequences from different clusters of both trees were selected to analyze different RS genes and identify those that were induced by UV light. Sequences RSArAs01, RSArAs02, RSArAs06, RSArAhT05, RSArAhT06 were placed in different clusters as it can be seen in Figure 1. A. hypogaea and A. stenosperma sequences were chosen to primer design

Genetics and Molecular Research 16 (3): gmr16039802 
among the species that had amplicons sequenced since the first is the cultivated and previous data on RS expression is available (Chung et al., 2003; Zhu et al., 2014) and the second is a source of genes for A. hypogaea, since some of its accessions had more resistance to some diseases that affect the cultivated one (Fávero et al., 2009).

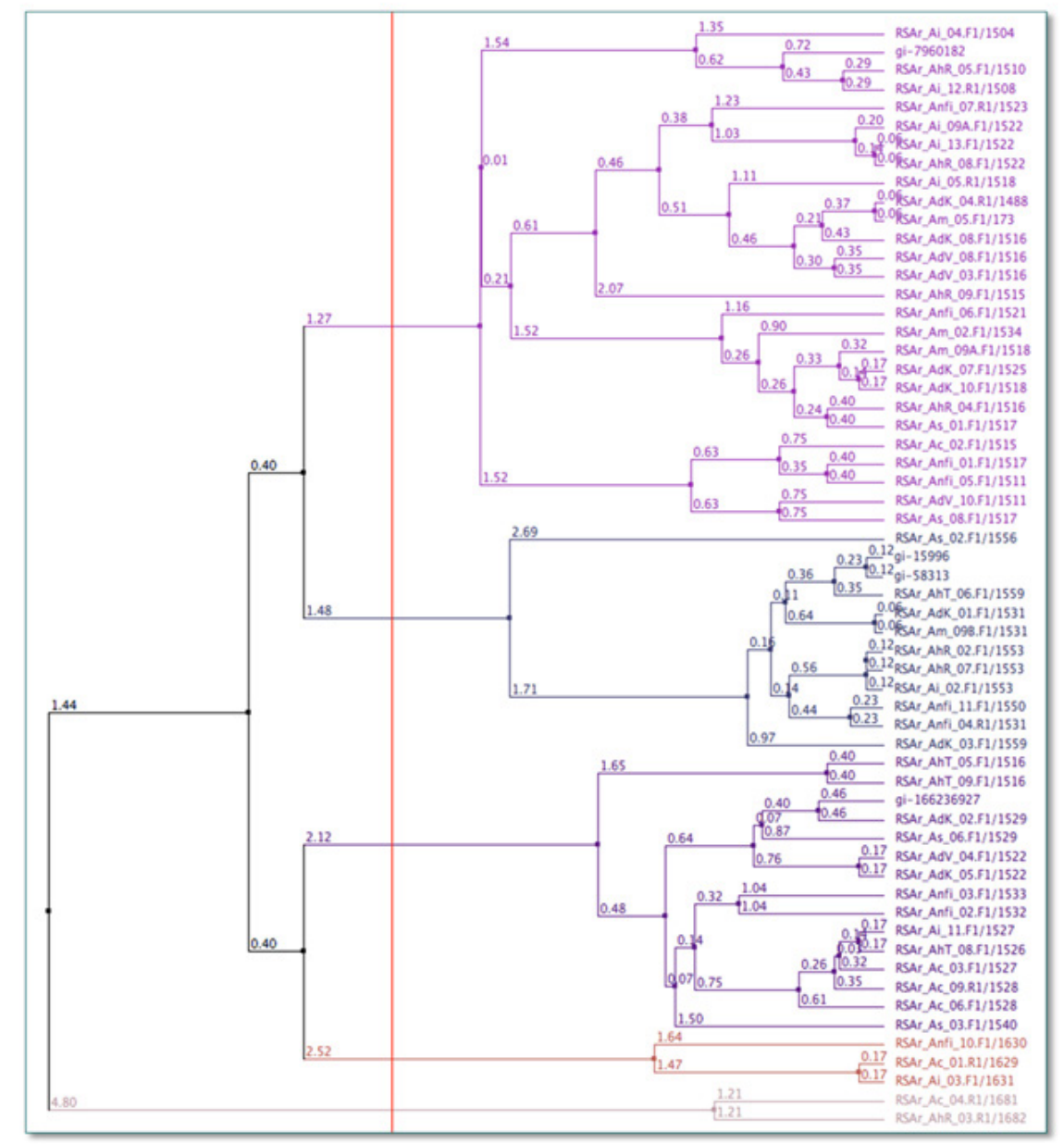

Figure 1. Phylogenetic tree obtained using DNA sequences of the fragments amplified through degenerate primers for Arachis RS (RSAR) and DNAs of six species of Arachis and a synthetic amphidiploid (A. hypogaea, A. cardenasii, A. duranensis, A. magna, A. stenosperma, A. ipaënsis, A. duranensis, A.ipaënsis) and RS sequences from GenBank (gi).

Eight of the nine pairs allowed the amplification of one specific sequence that had the expected size (150-200 bp) in all samples. The primer pair RSGbAsA12 resulted in two peaks (data not shown) indicating no specificity and it was not used for further analysis. The sequences of RS used for primer designing are probably in coding regions with important biological functions and therefore these sequences have been maintained in all species over time, before the emergence of different genomes in Arachis section.

Genetics and Molecular Research 16 (3): gmr16039802 
RSGbAhT14, RSArAhT5, RSArAs2 and RSArAs6 allowed the identification of genes that were upregulated in samples treated with UV and RSArAs01, RSArAhT06, RSGensteA06b, and RSGenhypTG08 showed no differential expression between test and control in all four genotypes analyzed (Table 2).

\section{Resveratrol content}

The resveratrol content in each genotype samples was also assessed. Only traces of resveratrol were detected in all control samples, not allowing quantification. On the other hand, resveratrol was detected in all UV-treated leaves (Table 3).

Table 3. Relative frequencies of four transcripts and resveratrol content in UV-treated leaves in four Arachis genotypes. The superscript letters $(\mathrm{a}, \mathrm{b}$ and $\mathrm{c})$ indicate significant differences among resveratrol contents.

\begin{tabular}{l|c|c|c|c|c}
\hline \multirow{2}{*}{ Sample } & \multicolumn{4}{|c|}{ RT-qPCR (Normalized values) } & \multirow{2}{*}{ HPLC $(\mu \mathrm{g} / \mathrm{g})$} \\
\cline { 2 - 6 } & RSArAs02 & RSArAhT05 & RSArAhT06 & RSGenAhT14 & \\
\hline A. hypogaea & 2.58 & 2.6 & 1.97 & 7.73 & $211.73^{\mathrm{a}}$ \\
\hline Synthetic allotetraploid & 6.4 & 7.72 & 14.96 & 14.93 & $193.66^{\mathrm{b}}$ \\
\hline A. duranensis & 30.17 & 15.21 & 15.29 & 30.13 & $371.97^{\mathrm{c}}$ \\
\hline A. ipaënsis & 58.84 & 116.71 & 29.47 & 58.84 & $225.85^{\mathrm{a}}$ \\
\hline
\end{tabular}

The superscript letters ( $\mathrm{a}, \mathrm{b}$ and $\mathrm{c}$ ) indicate significant differences among resveratrol contents.

Data showed that accessions of A. ipaënsis and A. duranensis have higher concentrations of resveratrol than the two allotetraploids, which is a surprising result since many other studies showed differences between diploids and polyploids, the latter having better characteristics than the former (Fávero et al., 2009; Xu et al., 2014; Michelotto et al., 2015; Leal-Bertioli et al., 2015, 2017). The lack of polyploidy superiority has been previously observed for Arabidopsis thaliana and Pyrus communis, in which only a few metabolites differ between diploids and synthetic autotetraploids. The authors suggest that the higher amount of metabolites observed in naturally occurring polyploids may be due to secondary natural selection (Tsukaya et al., 2015). In the current case, this explains the lower amount of resveratrol in the synthetic allotetaploid, but not in the naturally occurring peanut. The lack of polyploidy superiority may be attributed to the time required for adjustment, adaptation, and evolution after the genomic shock induced by polyploidization (Caruso et al., 2013). Furthermore, since there is evidence on variation to UV stimulus (Correia et al., 1999) and if that variation to biotic stress response is reflected on gene expression pattern, the smaller production found in polyploids may be due to different reasons such as the variation on sensibility among the samples analyzed to UV stimulus, resulting in early and delayed responses. Therefore, a large set of Arachis diploids and allopolyploids must be analyzed to have a better view of the impact of polyploidization on resveratrol content variation.

\section{RS gene expression and resveratrol content}

The relationships between relative frequencies of transcripts identified using primers RSArAs2, RSGbAhT14, RSArAhT5, and RSArAs6 and the amount of resveratrol in each biological replicate of each genotype analyzed are shown in Figure 2. The samples were more scattered when resveratrol content was plotted against relative frequencies of transcripts

Genetics and Molecular Research 16 (3): gmr16039802 
detected using primer pairs RSArAhT5 and RSArAs6. Grape has a RS gene family and the alleles have different behaviors under different treatments (Vannozzi et al., 2012). Thus, primers may have detected other RS genes that not have relationship with RS induction by UV, may being induced by other stimuli or they may be similar to a RS gene, like chalcone synthase genes.
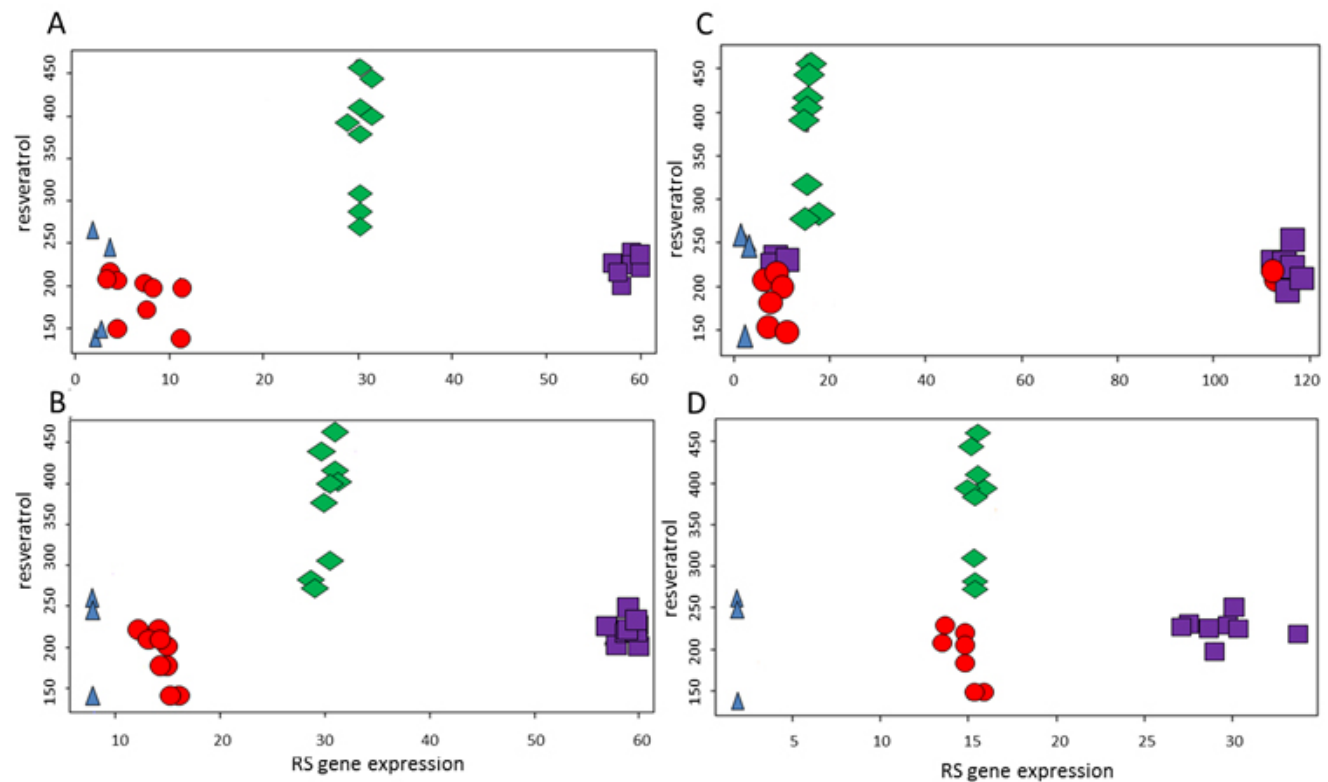

Figure 2. Relationship between the concentration of resveratrol and the relative expression levels of resveratrol synthase identified by the primers pairs RSArAs2 (A), RSGbAhT14 (B), RSArAhT5 (C), and RSArAhT06 (D) to A. hypogaea (blue triangle), synthetic allotetraploid (red circle), A. duranensis (green diamond), A. ipaënsis (purple square).

Biological replicates of each genotype had similar expression patterns for RSArAs2 and RSGbAhT14, suggesting those are part of a RS gene that were induced by UV treatment and they may amplify parts of the same genes. The function of these genes was previously validated by transgenic studies with Nicotiana benthamiana (Condori et al., 2009).

Previous analysis of RS in peanuts has been done using Southern blot (Lanz et al., 1990), but wild Arachis species RS had never been analyzed, so this is the first report of the use of RT-qPCR to analyze RS in cultivated and wild Arachis species. The use of sequences for primer design from different clusters in the tree (Figure 1) and the establishment of relation with resveratrol content was a successful approach to the identification of primers that allowed the analysis of the mRNA of genes involved in resveratrol synthesis under UV induction.

The behavior of the synthetic allotetraploid was similar to natural tetraploid ( $A$. hypogaea) and when compared to the two species both showed low relative expression and production of resveratrol (Figure 2). A. duranensis showed higher concentrations of resveratrol, but the value of the relative expression was lower when compared to other samples analyzed. Arachis ipaënsis had intermediate concentrations of resveratrol despite it had the highest values of relative expression. Positive correlation between resveratrol content and level of a 
RS mRNA was observed in A. hypogaea and that was explained by transcriptional control of RS activity (Chung et al., 2003). Based on the assumption diploids and synthetic allotetraploid have similar behavior to A. hypogaea, the higher expression of RS on tetraploids may have happened $15 \mathrm{~h}$ after treatment, since low relative expression and production of resveratrol. A. duranensis had the highest level of resveratrol in relation the other analyzed species when compared with the others three genotypes analyzed the values of genetic expression was lower than in A. ipaënsis. If $A$. duranensis has similar behavior to the cultivated peanut, the data suggested that larger amounts of resveratrol may be found before $15 \mathrm{~h}$, because the transcript levels compared to found in the other species were not the highest observed, suggesting the beginning of a reduction in its expression. The results suggested a late induction in A. ipaënsis since the transcript levels were the highest and the resveratrol level was the lowest at the collection point. If $A$. ipaënsis has behavior similar to A. hypogaea, the best point for analysis of resveratrol in this species can be reached $15 \mathrm{~h}$ after treatment. This was also observed in species of grapevine (wild and cultivated) one sequence of RS had different expression levels in various hours post inoculation with Uncinula necator for each genotype, showing a speciesspecific expression profile (Xu et al., 2011).

This is the study trial of RS using RT-qPCR in Arachis and the first one in wild Arachis species. The successful results here obtained will allow future studies including more periods after induction to understand better the kinetics of resveratrol production and its relationship with resveratrol synthase control.

\section{ACKNOWLEDGMENTS}

We would like to thank Embrapa for the financial support.

\section{REFERENCES}

Baur JA and Sinclair DA (2006). Therapeutic potential of resveratrol: the in vivo evidence. Nat. Rev. Drug Discov. 5: 493506. https://doi.org/10.1038/nrd2060

Bechara MD, Moretzsohn MC, Palmieri DA, Monteiro JP, et al. (2010). Phylogenetic relationships in genus Arachis based on ITS and 5.8S rDNA sequences. BMC Plant Biol. 10: 255. https://doi.org/10.1186/1471-2229-10-255

Bertioli DJ, Cannon SB, Froenicke L, Huang G, et al. (2016). The genome sequences of Arachis duranensis and Arachis ipaensis, the diploid ancestors of cultivated peanut. Nat. Genet. 48: 438-446. https://doi.org/10.1038/ng. 3517

Caruso I, Dal Piaz F, Malafronte N, De Tommasi N, et al. (2013). Impact of ploidy change on secondary metabolites and photochemical efficiency in Solanum bulbocastanum. Nat. Prod. Commun. 8: 1387-1392.

Chang S, Puryear J and Cairney J (1993). A simple and efficient method for isolating RNA from pine trees. Plant Mol. Biol. Rep. 11: 113-116.

Chung IM, Park MR, Chun JC and Yun SJ (2003). Resveratrol accumulation and resveratrol synthase gene expression in response to abiotic stresses and hormones in peanut plants. Plant Sci. 164: 103-109. https://doi.org/10.1016/S0168$\underline{9452(02) 00341-2}$

Condori J, Medrano G, Sivakumar G, Nair V, et al. (2009). Functional characterization of a stilbene synthase gene using a transient expression system in planta. Plant Cell Rep. 28: 589-599. https://doi.org/10.1007/s00299-008-0664-0

Correia CM, Areal ELV, Torres-Pereira MS and Torres-Pereira JMG (1999). Intraspecific variation in sensitivity to ultraviolet - B radiation in maize grown under field conditions. Field Crops Res. 62: 97-105. https://doi.org/10.1016/ $\underline{\text { S0378-4290(98)00164-6 }}$

Fávero AP, Moraes SAD, Garcia AAF, Valls JFM, et al. (2009). Characterization of rust, early and late leaf spot resistance in wild and cultivated peanut germplasm. Sci. Agric. 66: 110-117. https://doi.org/10.1590/S0103-90162009000100015

Fredslund J, Schauser L, Madsen LH, Sandal N, et al. (2005). PriFi: using a multiple alignment of related sequences to find primers for amplification of homologs. Nucleic Acids Res. 33: W516-20. https://doi.org/10.1093/nar/gki425

Hanhineva K, Kokko H, Siljanen H, Rogachev I, et al. (2009). Stilbene synthase gene transfer caused alterations in the

Genetics and Molecular Research 16 (3): gmr16039802 
phenylpropanoid metabolism of transgenic strawberry (Fragaria x ananassa). J. Exp. Bot. 60: 2093-2106. https://doi. org/10.1093/jxb/erp085

Huang XQ, Guo LQ, Li XM, Lin JF, et al. (2012). Cloning and sequence analysis of resveratrol synthase gene from peanut (Arachis hypogaea L.). Biotechnol. Bull. 3: 69-74.

Ingham JL (1976). 3, 5, 4'-Trihydroxystilbene as a phytoalexin from groundnuts (Arachis hypogaea). Phytochemistry 15: 1791-1793. https://doi.org/10.1016/S0031-9422(00)97494-6

Jain M, Nijhawan A, Tyagi AK and Khurana JP (2006). Validation of housekeeping genes as internal control for studying gene expression in rice by quantitative real-time PCR. Biochem. Biophys. Res. Commun. 345: 646-651. https://doi. org/10.1016/j.bbrc.2006.04.140

Jeandet P, Delaunois B, Aziz A, Donnez D, et al. (2012). Metabolic engineering of yeast and plants for the production of the biologically active hydroxystilbene, resveratrol. J. Biomed. Biotechnol. 2012: 579089. https://doi. org/10.1155/2012/579089

Kochert G, Stalker H, Gimenes M, Galgaro L, et al. (1996). RFLP and cytogenetic evidence on the origin and evolution of allotetraploid domesticated peanut Arachis hypogaea (Leguminosae). Am. J. Bot. 83: 1282-1291. https://doi. org $/ 10.2307 / 2446112$

Krapovickas A and Gregory WC (2007). Taxonomy of the genus Arachis (Leguminosae). Bonplandia 16 (Suppl): 1-205.

Kumar G, Purty RS, Sharma MP, Singla-Pareek SL, et al. (2009). Physiological responses among Brassica species under salinity stress show strong correlation with transcript abundance for SOS pathway-related genes. J. Plant Physiol. 166: 507-520. https://doi.org/10.1016/j.jplph.2008.08.001

Lanz T, Schröder G and Schröder J (1990). Differential regulation of genes for resveratrol synthase in cell cultures of Arachis hypogaea L. Planta 181: 169-175. https://doi.org/10.1007/BF02411534

Leal-Bertioli SCM, Santos SP, Dantas KM, Inglis PW, et al. (2015). Arachis batizocoi: a study of its relationship to cultivated peanut (A. hypogaea) and its potential for introgression of wild genes into the peanut crop using induced allotetraploids. Ann. Bot. 115: 237-249. https://doi.org/10.1093/aob/mcu237

Leal-Bertioli SCM, Moretzsohn MC, Santos SP, Brasileiro ACM, et al. (2017). Phenotypic effects of allotetraploidization of wild Arachis and their implications for peanut domestication. Am. J. Bot. 104: 379-388. https://doi.org/10.3732/ ajb. 1600402

Lopes RM, Silveira D, Gimenes MA, Vasconcelos PAS, et al. (2013). Characterization of resveratrol content in ten wild species of section Arachis, genus Arachis. Genet. Resour. Crop Evol. 60: 2219-2226. https://doi.org/10.1007/s10722013-9987-y

Luo M, Dang P, Bausher MG, Holbrook CC, et al. (2005). Identification of transcripts involved in resistance responses to leaf spot disease caused by Cercosporidium personatum in peanut (Arachis hypogaea). Phytopathology 95: 381-387. https://doi.org/10.1094/PHYTO-95-0381

Michelotto MD, Barioni W, Jr., de Resende MDV, de Godoy IJ, et al. (2015). Identification of fungus resistant wild accessions and interspecific hybrids of the genus Arachis. PLoS One 10: e0128811. https://doi.org/10.1371/journal. pone. 0128811

Morgante CV, Guimarães PM, Martins AC, Araújo AC, et al. (2011). Reference genes for quantitative reverse transcriptionpolymerase chain reaction expression studies in wild and cultivated peanut. BMC Res. Notes 4: 339. https://doi. org/10.1186/1756-0500-4-339

Pande S and Rao JN (2001). Resistance of wild Arachis species to late leaf spot and rust in greenhouse trials. Plant Dis. 85: 851-855. https://doi.org/10.1094/PDIS.2001.85.8.851

Pfaffl MW, Horgan GW and Dempfle L (2002). Relative expression software tool (REST) for group-wise comparison and statistical analysis of relative expression results in real-time PCR. Nucleic Acids Res. 30: e36. https://doi.org/10.1093/ $\underline{\text { nar/30.9.e36 }}$

Potrebko I and Resurreccion AVA (2009). Effect of ultraviolet doses in combined ultraviolet-ultrasound treatments on trans-resveratrol and trans-piceid contents in sliced peanut kernels. J. Agric. Food Chem. 57: 7750-7756. https://doi. org/10.1021/j9900667d

Schröder G, Brown JW and Schröder J (1988). Molecular analysis of resveratrol synthase. cDNA, genomic clones and relationship with chalcone synthase. Eur. J. Biochem. 172: 161-169. https://doi.org/10.1111/j.1432-1033.1988. $\underline{\text { tb13868.x }}$

Tsukaya H, Sawada Y, Oikawa A, Shiratake K, et al. (2015). Intraspecific comparative analyses of metabolites between diploid and tetraploid Arabidopsis thaliana and Pyrus communis. New Negatives Plant Sci. 1: 53-61. https://doi. org/10.1016/j.neps.2015.06.001

Untergasser A, Cutcutache I, Koressaar T, Ye J, et al. (2012). Primer3 - new capabilities and interfaces. Nucleic Acids Res. 40: e115. https://doi.org/10.1093/nar/gks596

Genetics and Molecular Research 16 (3): gmr16039802 
Valls JF, Costa LC and Custodio AR (2013). A novel trifoliolate species of Arachis (Fabaceae) and further comments on the taxonomic section Trierectoides. Bonplandia 22: 91-97.

Vannozzi A, Dry IB, Fasoli M, Zenoni S, et al. (2012). Genome-wide analysis of the grapevine stilbene synthase multigenic family: genomic organization and expression profiles upon biotic and abiotic stresses. BMC Plant Biol. 12: 130. https://doi.org/10.1186/1471-2229-12-130

Wu H, Wang Q, Ma T and Ren J (2009). Comparative studies on the functional properties of various protein concentrate preparations of peanut protein. Food Res. Int. 42: 343-348. https://doi.org/10.1016/j.foodres.2008.12.006

Xu CG, Tang TX, Chen R, Liang CH, et al. (2014). A comparative study of bioactive secondary metabolite production in diploid and tetraploid Echinacea purpurea (L.) Moench. Plant Cell Tissue Organ Cult. 116: 323-332. https://doi. org/10.1007/s11240-013-0406-Z

Xu W, Yu Y, Zhou Q, Ding J, et al. (2011). Expression pattern, genomic structure, and promoter analysis of the gene encoding stilbene synthase from Chinese wild Vitis pseudoreticulata. J. Exp. Bot. 62: 2745-2761. https://doi. org $/ 10.1093 / \mathrm{jxb} / \mathrm{erq} 447$

Zhao S and Fernald RD (2005). Comprehensive algorithm for quantitative real-time polymerase chain reaction. J. Comput. Biol. 12: 1047-1064. https://doi.org/10.1089/cmb.2005.12.1047

Zhu F, Han J, Liu S, Chen X, et al. (2014). Cloning, expression pattern analysis and subcellular localization of resveratrol synthase gene in peanut (Arachis hypogaea L.). Am. J. Plant Sci. 5: 3619-3631. https://doi.org/10.4236/ ajps.2014.524378

Genetics and Molecular Research 16 (3): gmr16039802 